University of Nebraska - Lincoln

DigitalCommons@University of Nebraska - Lincoln

Publications from USDA-ARS / UNL Faculty

U.S. Department of Agriculture: Agricultural

Research Service, Lincoln, Nebraska

1988

Male Sterility In Soybean-An Overview

Robert Graybosch

University of Nebraska-Lincoln, bob.graybosch@ars.usda.gov

Reid G. Palmer

University of Nebraska-Lincoln

Follow this and additional works at: https://digitalcommons.unl.edu/usdaarsfacpub

Part of the Agricultural Science Commons

Graybosch, Robert and Palmer, Reid G., "Male Sterility In Soybean-An Overview" (1988). Publications from USDA-ARS / UNL Faculty. 904.

https://digitalcommons.unl.edu/usdaarsfacpub/904

This Article is brought to you for free and open access by the U.S. Department of Agriculture: Agricultural Research Service, Lincoln, Nebraska at DigitalCommons@University of Nebraska - Lincoln. It has been accepted for inclusion in Publications from USDA-ARS / UNL Faculty by an authorized administrator of DigitalCommons@University of Nebraska - Lincoln. 


\title{
MALE STERILITY IN SOYBEAN-AN OVERVIEW ${ }^{1}$
}

\author{
Robert A. Graybosch and Reid G. Palmer \\ USDA-ARS, Department of Agronomy, University of Nebraska, Lincoln, Nebraska 68583; \\ and USDA-ARS, Departments of Agronomy and Genetics, \\ Iowa State University, Ames, Iowa 50011
}

\begin{abstract}
A B S T R A C T
The most common type of reproductive mutations observed in the soybean [Glycine max (L.) Merr.] are those that induce male sterility. The high frequency of occurrence of male-sterile mutations indicates that a number of genes influence the processes of microgametogenesis and microsporogenesis. The current knowledge of these mutations is summarized. The origins of male-sterile mutations, their inheritance patterns, and known linkage relationships are detailed. The phenotypic expression of male-sterile mutations, including their effects on both male and female reproduction, is discussed. The influence of environment on the expressivity of malesterile mutations, and the effects of male-sterile mutations on physiological processes (senescence and nitrogen fixation) are summarized. Male-sterile mutations have been useful in the study of soybean reproduction, genetic and cytogenetic investigations, and in evaluating the potential for commercial production of hybrid soybeans. These various applications of male-sterile mutations are presented.
\end{abstract}

SEED PRODUCTION by self-pollinated crops is dependent upon concerted development of both male and female reproductive structures, and successful pollination and fertilization. Genetic mutations that inhibit developmental processes within either stamens or pistils can result in reproductive sterility. Sterility-inducing mutations of soybean [Glycine $\max$ (L.) Merr.] are of two types. Male-sterile, femalefertile (MS-FF) mutations selectively eliminate male reproductive function while female reproductive capacity either is unaffected or is only slightly reduced. Male-sterile, femalesterile (MS-FS) mutations virtually abolish both male and female reproduction.

Such mutations are fundamentally different from F1 sterility observed in interspecific hybrids within the genus Glycine. Reproductive sterility in such hybrids arises through the failure of homologous chromosome pairing during meiosis and is not a consequence of single gene mutations (Newell and Hymowitz, 1983). MS$\mathrm{FF}$ and MS-FS mutations arise through mutations in single Mendelian loci. These mutations might induce the failure of homologous chromosome pairing during meiosis, but do so through the absence of a specific gene product.

\footnotetext{
${ }^{1}$ Received for publication 9 February 1987; revision accepted 26 August 1987.

Joint contribution: Agricultural Research Service, U.S. Department of Agriculture, and Journal Paper No. J-12771 of the Iowa Agriculture and Home Economics Experiment Station, Ames, IA 50011. USDA Project 2763.

Portions of this work were completed by RAG while employed by Monsanto Agricultural Company, St. Louis, MO. The authors thank an anonymous reviewer for helpful comments on the manuscript.
}

Interspecific F1 sterility in Glycine likely arises as a consequence of genome diversification between the contributing parents.

More than $95 \%$ of the seed produced by wildtype soybean plants is the result of autogamy, though the soybean flower has retained features that render it attractive to insect pollinators (Erickson, 1975; Erickson and Garment, 1979). In plants carrying MS-FF mutations, seed production is possible if insect vectors and pollen donors are available. In contrast, soybean plants carrying MS-FS mutations rarely set seed. Sterility in such plants either is due to abnormalities of floral organogenesis that prevent both autogamy and allogamy (Johns and Palmer, 1982) or to the interruption of homologous pairing of chromosomes during meiosis through asynapsis or desynapsis (Hadley and Starnes, 1964; Palmer, 1974a; Palmer and Kaul, 1983). Seed production by such plants may occur through the infrequent formation of eggs with a complete, or nearly complete, chromosome complement as a consequence of nuclear restitution.

The absolute sterility of MS-FS types limits their potential for application to soybean breeding and genetics. However, the few viable ovules produced by these mutants often generate aneuploid or polyploid seedlings (Palmer 1974b; Palmer and Heer, 1976) useful in linkage analyses. MS-FF lines are of greater utility because the potential for the generation of seed via outcrossing is retained. Consequently, the intent of this discussion is to summarize the available knowledge regarding MS-FF soybean plants. It is hoped that this will allow researchers to select the mutation best suited to their 
TABLE 1. Origin of male-sterile female-fertile mutations of soybean

\begin{tabular}{|c|c|c|c|}
\hline Mutation & $\begin{array}{l}\text { Genetic type } \\
\text { collection } \\
\text { number }\end{array}$ & Reference & Location and genetic background of mutation \\
\hline msl (North Carolina) & $\mathrm{T} 260 \mathrm{H}$ & Brim and Young, 1971 & North Carolina, varietal origin unknown \\
\hline$m s l$ (Urbana) & $\mathrm{T} 266 \mathrm{H}$ & Boerma and Cooper, 1978 & Urbana, Illinois, F3 of L67-533 $\times$ SRF 300 \\
\hline$m s l$ (Tonica) & $\mathrm{T} 267 \mathrm{H}$ & Palmer et al., $1978 \mathrm{a}$ & Tonica, Illinois, cv Harosoy \\
\hline$m s 1$ (Ames 1) & $\mathrm{T} 268 \mathrm{H}$ & Palmer et al., 1978a & Ames, Iowa, T258H \\
\hline$m s 1$ (Ames 2) & - & Skorupska and Palmer, 1987 & $\begin{array}{l}\text { Ames, Iowa, germplasm population } \\
\text { AP6(S1)C1 }\end{array}$ \\
\hline msl (China) & - & Yee and Jian, 1983 & China, L-78-387 \\
\hline$m s 2$ & $\mathrm{~T} 259 \mathrm{H}$ & Graybosch et al., 1984 & Eldorado, Illinois, F3 of SL1 $1 \times$ L66L-77 \\
\hline$m s 3$ (Washington) & $\mathrm{T} 273 \mathrm{H}$ & Palmer et al., 1980 & $\begin{array}{l}\text { Washington, Iowa, F3 of cv Calland } \times \mathrm{cv} \\
\text { Cutler }\end{array}$ \\
\hline$m s 3$ (Flanagan) & $\mathrm{T} 284 \mathrm{H}$ & $\begin{array}{l}\text { Chaudhari and Davis, } 1977 \\
\text { Graybosch and Palmer, } 1987\end{array}$ & Flanagan, Illinois, cv Wabash \\
\hline$m s 4$ & $\mathrm{~T} 274 \mathrm{H}$ & Delannay and Palmer, 1982 & Ames, Iowa, cv Rampage \\
\hline$m s 5$ & $\mathrm{~T} 277 \mathrm{H}$ & Buss, 1983 & Blacksburg, Virginia, cv Essex \\
\hline$m s p$ & $\mathrm{~T} 271 \mathrm{H}$ & Stelly and Palmer, 1980 & $\begin{array}{l}\text { Ames, Iowa, germplasm population } \\
\text { AP6(S1)Cl }\end{array}$ \\
\hline
\end{tabular}

goals and stimulate further investigations on the reproductive biology of the soybean. This review is limited to mutations for which gene symbols have been assigned by the Soybean Genetics Committee. These mutations are maintained as heterozygous lines segregating for male-sterility. Collections are housed in the USDA Genetic Type Collection, under the direction of Dr. R. L. Bernard, USDA-ARS, University of Illinois, Urbana, IL.

ORIGIN, INHERITANCE, AND LINKAGE RELATIONSHIPS-The available MS-FF mutations, with the exception of $m s 5$, arose spontaneously in field plantings or breeding populations. The $m s 5$ mutation was induced through mutagenesis (Buss, 1983). Two putative male-sterile mutations have been recovered from tissueculture-derived lines, but gene symbols have yet to be assigned (Graybosch, Edge, and Delannay, 1987a). Field-grown male-sterile soybean plants are recognized by a number of phenotypic characteristics, including diminished pod production, the presence of seedless parthenocarpic ("vestigial") pods, a high frequency of one-seeded and two-seeded pods (male-fertile soybean plants typically produce three-seeded or four-seeded fruit), and the retention of chlorophyll by leaves after seeds have attained physiological maturity. However, references to this battery of features as the "malesterile phenotype" are erroneous. Similar features may be induced through viral or bacterial infections, MS-FS mutations, polyploidy, or chemical pollen sterilants.

To date, MS-FF mutations have been mapped to six distinct, independent loci. Plants homozygous recessive for mutations at any one locus are male sterile. In addition, six independent occurrences of mutations at the $m s 1$ locus (Palmer, Winger, and Albertsen, 1978a; Skorupska and Palmer, 1987) and two occurrences at the $m s 3$ locus (Graybosch and Palmer, 1987) have been reported. Mutations at the remaining loci have been isolated once. The Soybean Genetics Committee has suggested that independent mutations at known loci be distinguished by a name designating the place of origin, the cultivar of origin, or some other feature that identifies the occurrence. In accordance with this proposal, independent mutations at male-sterility loci are designated by the place of origin. Table 1 lists the origins of the various male-sterile mutations.

All MS-FF mutations of soybean are inherited as monogenic recessive characters. Measurable and repeatable effects of these mutations in the heterozygous state have not been observed, although some influence of $m s 1$ on female reproduction in heterozygotes is suspected. (See section on EFFECTS ON FEMALE REPRODUCTION.) Male fertility in heterozygotes equals that of homozygous dominant plants. Thus, these mutations act to interrupt pollen development during the sporophytic stage of the life cycle rather than the gametophytic stage.

Cytoplasmic male sterility (CMS) has been reported in soybean. Davis (1985) describes the production of CMS through the combination of the cytoplasm from the cultivar Elf (cytsR1R1R2R2) with two distinct pairs of recessive genes for male sterility ( $r 1 r 1$ and $r 2 r 2)$. The cultivar Bedford served as the source of $r 1 r 1 ; r 2 r 2$ was derived from the cultivar Braxton. Individuals of the genotype cytsr1r1r2r2 would be male sterile. Fertility is restored by 
the presence of a single dominant allele at either the $R 1$ or $R 2$ locus. The Soybean Genetics Committee has not approved gene symbols for either the cytoplasmic or the nuclear restorer genes of this system.

The MS-FF mutations are inherited independently of each other. Only $m s l$ has been placed in a linkage group. The $m s l$ locus is situated in Linkage Group 8, along with the genetic markers $w 1, w m$, st 5 , and the breakpoint of a translocation from Glycine soja Sieb. \& Zucc. (Palmer and Kaul, 1983). Through the use of two independent reciprocal translocations, Linkage Group 8 has been assigned to the satellite chromosome, the only morphologically distinct chromosome in the soybean karyotype (Sacks and Sadanaga, 1984).

EFFECTS ON MALE REPRODUCTION - The analysis of the effects of male-sterile mutations has provided information regarding structures and functions essential to the processes of anther and pollen wall genesis. Observations on the developmental reproductive cytology of malesterile plants have been reported for five of the MS-FF mutations (Albertsen and Palmer, 1978; Palmer, Johns, and Muir, 1980; Delannay and Palmer, 1982; Stelly and Palmer, 1982; Buntman and Horner, 1983; Graybosch and Palmer, 1985a, b, 1987). The MS-FF mutations do not suppress the gross differentiation of anthers. Rather, anthers form, but they are incapable of generating viable pollen. Pollen development is arrested at a mutation-specific stage.

Pollen differentiation in male-fertile soybean is the result of successful development of two distinct tissue layers within the anther, the tapetum and the reproductive cells. The latter is a collective term referring to the meiocytes (microspore mother cells) and their meiotic products, the microspores and pollen grains. Meiocytes arise from a cylinder of meristematic cells (sporogenous cells) in the center of each anther locule. During the process of meiosis, the meiocytes are enclosed by a sheath of callose, a polysaccharide material secreted exterior to the plasmalemma but interior to the primary cell wall. Each meiocyte generates a tetrad (quartet) of microspores. Formation of the pollen wall is initiated while the microspores are encased with callose. The dissolution of callose liberates the microspores, each of which subsequently matures and develops to form a single pollen grain. Each soybean anther generates between 300 and 800 pollen grains (Palmer, Albertsen, and Heer, 1978b). Pollen grains bear a smooth tricolpate wall of sporopollenin and contain reserves of starch and lipids. The pol- len wall consists of a cellulosic intine adjacent to the plasmalemma, surrounded by a bilayer of sporopollenin. This bilayer is composed of an endexine and an ektexine. The latter, in turn, is formed by the deposition of three concentric zones, the pedium, the columellae, and the tectum. Pollen is bicellular at anthesis.

The tapetum constitutes a single cell layer surrounding the reproductive cells. The tapetum presumably controls the flow of nutrients from the somatic cells of the anther to the reproductive cells. It reaches its maximal stage of maturity at the tetrad stage of microsporogenesis. At this time, the tapetum is devoid of an inner tangential cell wall, bears an undulating plasmalemma, and contains large quantities of endoplasmic reticulum and Golgi bodies. Ubisch bodies do not form. Thus, the structure of the tapetum identifies its role as secretion. The tapetum later senesces as metabolites accumulate within the pollen grains.

In soybean, male sterility may result from dysfunction of either the tapetum or the reproductive cells, or both. All independent mutations at the $m s 1$ locus induce male sterility by acting on the function of the reproductive cells alone. The process of postmeiotic cytokinesis is omitted (Albertsen and Palmer, 1978). However, the absence of cytokinesis results in the production of quadrinucleate (coenocytic) microspores (CM). These cells produce walls of sporopollenin and engorge with reserve materials in the same fashion as viable pollen grains. However, CM's are not released readily from the anther. A matrix of unknown origin prevents the release of CM's even though the anthers dehisce properly. Coenocytic microspores differentiate colpi, but the number and distribution of these structures is variable. Pollen tubes are generated by CM's both in vitro and in vivo, but whether these tubes can participate in the release of sperm and fertilization of ovules remains unclear (Albertsen and Palmer, 1978; Skorupska and Nawracala, 1980; Chen, Albertsen, and Palmer, 1987). The fate of the four nuclei contained within each $\mathrm{CM}$ has not been established. However, mitotic divisions have been detected at a developmental stage approximating that of microspore mitosis in male-fertile plants. In $\mathrm{ms} 1$ male-sterile plants, the absence of postmeiotic cytokinesis is the only observable phenotypic abnormality. Tapetal differentiation and pollen-wall formation are identical to that of malefertile plants.

The process of postmeiotic cytokinesis also is influenced by the $m s 4$ mutation, but pollen wall differentiation is rendered abnormal as well (Delannay and Palmer, 1982; Graybosch 
and Palmer, 1985b). The nature of postmeiotic cytokinesis in reproductive cells is variable. The process occurs, in some form, in approximately $75 \%$ of all reproductive cells examined, though cell plates frequently are incomplete or irregular in orientation. In $3.3 \%$ of the anther locules examined, postmeiotic cytokinesis was complete and properly oriented, resulting in the formation of functional pollen grains. Temperature influences the process, though a precise correlation between temperature and frequency of cytokinesis has not been determined. Pollen identical to that of male-fertile plants can arise from anthers of male-sterile plants. However, completion and correct orientation of cell plates do not assure the genesis of functional pollen because abnormalities in subsequent pollen wall formation may occur.

Postmeiotic reproductive cells demonstrate a wide range of variability in the extent of pollen-wall formation. Walls may be absent, represented by scattered accumulations of sporopollenin, consist of a mixture of stratified and disorganized sporopollenin deposits, or contain all the layers present in male-fertile pollen grains. Completion of the pollen wall seems dependent on the completion of cytokinesis. When cytokinesis is omitted, pollenwall formation is abnormal, in contrast to the situation in $m s 1$ male-sterile plants, in which normal pollen walls are generated in the complete absence of cytokinesis.

Abnormal cytokinesis associated with $m s 1$ and $m s 4$ might be correlated with aberrant cytoskeletal differentiation. In Lilium, disruption of microtubule formation with colchicine resulted in the production of multinucleate or partly divided microspores if the drug was applied during meiosis (Sheldon and Dickinson, 1986). Colpi formation also was rendered abnormal; otherwise, pollen wall formation was not affected. Thus, colchicine treatment can result in a pattern of microspore differentiation similar to that induced by the $m s 1$ mutation. In $m s 4$, cytoskeletal abnormalities also might be induced. However, the abnormalities of pollen-wall formation may be indicative of malfunction of the plasmalemma. Sheldon and Dickinson (1983) suggested that pollen-wall formation in Lilium is dependent upon the insertion of "pre-pattern determinants" in the cell membrane during the meiotic period. $\mathrm{Ab}$ sence of such determinants, or substances interacting with such determinants, might be involved in $m s 4$-induced sterility. However, a potential role for the cytoskeleton in the $m s 4$ system cannot be ignored. Van Lammeren et al. (1985) studied cytoskeletal organization during pollen formation in Gasteria. At the tetrad stage, there was a distinct organization of microtubules radiating from each daughter nucleus toward the region of cell-plate formation. The region in which cell-plate formation occurred was free of microtubules. The orientation of the cell plates appeared dependent upon this arrangement of microtubules. Thus, the $m s 4$ mutation might have pleiotropic effects in that it influences both microtubule formation (and, hence, cytokinesis) and plasmalemma function and subsequent pollen-wall genesis. Observations of microtubule formation in male-sterile soybean plants, however, have not been obtained. Application of the immunocytochemical techniques employed by Van Lammeren et al. (1985) and Sheldon and Dickinson (1986) to the study of the $m s 1$ and ms 4 mutations might be useful in evaluating the role of the cytoskeleton in male sterility.

Male sterility resulting from the $m s p$ and $m s 2$ mutations may be attributed to malfunctions of the tapetal layer. The cytological effects of $m s p$ are variable (Stelly and Palmer, 1982). The abortion of reproductive cells is observed at all stages of anther development. Tapetal abnormalities, typically in the form of premature vacuolation and/or cellular collapse, precede the abortion of reproductive cells.

The crucial role of the tapetum in the generation of viable pollen is most clearly elucidated by the phenotypic effects of the $m s 2$ mutation. Reproductive cells consistently degenerate at the tetrad stage (Graybosch et al., 1984; Graybosch and Palmer, 1985a). Meiotic karyokinesis and cytokinesis occur, but the cells degenerate after organizing probaculae, the primordial sporopollenin deposits characteristic of pollen-wall formation. No further differentiation of pollen walls occurs. The microspores abort while still encased in callose. Mature anthers contain degenerate microspores, and callose fails to dissolve. Ultrastructural observations (Graybosch and Palmer, 1985a) indicate that failure of the tapetal layer to differentiate properly is the cause of male sterility. The mature tapetum is represented by cells consisting of a large central vacuole, little cytoplasm, and few organelles. The inner tangential cell wall fails to dissolve, and the tapetum collapses along with the microspores.

Simultaneous abnormalities of the tapetum and reproductive cells occur in $m s 3$ male-sterile soybean (Palmer et al., 1980; Buntman and Horner, 1983; Graybosch and Palmer, 1987). Microspores are generated, and pollen walls are initiated. However, the microspores suddenly lose all cytoplasm and, at anther maturity, are represented by pollen walls surrounding empty space. Pollen-wall structure 
differs from that of male-fertile plants in the omission of the columellar layer. At the tetrad stage, tapetal cells seem normal. However, as microspore degeneration occurs, tapetal cells either collapse or accumulate an electron-dense material that bears staining and fluorescence properties of sporopollenin (Nakashima, Horner, and Palmer, 1984). Tapetal cells are the site of the synthesis of sporopollenin precursors (Horner and Pearson, 1978). Thus, the intercellular transport of these compounds from the tapetum to the microspores may be blocked in the $m s 3$ system. Conversely, the inability of the microspores to assimilate and metabolize sporopollenin precursors properly may lead to a source overload in the tapetum, which is followed by intracellular polymerization. Similar though less extensive deposits of sporopollenin were noted within the tapetum and anther locule of $m s 4$ male-sterile plants (Graybosch and Palmer, 1985b). Buntman and Horner (1983) described tapetal mitochondria as being abnormal in $m s 3$ male-sterile plants. However, Horner (personal communication) has since found that tapetal mitochondria condense and differentiate more cristae as anther maturation progresses. In $m s 3$, and in $m s 2$ tapeta (Graybosch and Palmer, 1985a), this process is delayed.

EFFECTS ON FEMALE REPRODUCTION-Sterility-inducing mutations of soybean vary in the degree of influence on the female reproductive system. MS-FS mutations effectively eliminate the ability of the plant to generate seed through the abolition of meiotic chromosome pairing. The MS-FF mutations are not without effect on female reproduction. The effects may be extensive, slight, or absent. By definition, a MS-FF mutation cannot eliminate female generative functions. However, abnormalities in chromosome number and/or embryo structure may occur in progeny of male-sterile plants.

Abnormalities of female reproduction most frequently are detected in plants carrying the ms 1 mutation. Male sterility in this system is the result of the failure of postmeiotic cytokinesis. Thus, it is not surprising that the aberrations associated with ovule and embryo ontogeny are the result of the frequent, but not obligate omission of postmeiotic cytokinesis during megasporogenesis (Kennell and Horner, 1985). Polyploid and polyembryonic seedlings are common among progeny of openpollinated male-sterile ( $m s 1 m s 1)$ plants (Kenworthy, Brim, and Wernsman, 1973; Beversdorf and Bingham, 1977; Chen, Heer, and Palmer, 1985). Chromosome numbers reported range from 20 to 200 (the normal diploid complement of soybean is $2 n=2 \times=40$ ). Haploids typically occur as members of polyembryonic seeds, whereas polyploids are found in both monoembryonic and polyembryonic seeds. Twins are the most common type of polyembryonic seedlings, but triplets, quadruplets, and quintuplets have been observed. Both Kenworthy et al. (1973) and Beversdorf and Bingham (1977) noted the occurrence of genetically different members of twin sets. This could result from either multiple pollination events or the apomictic development of one member of the set coupled with a sexual origin for the second member. The occurrence of androgenesis and the phenotypic expression of $m s 1$ in the heterozygous condition have been suggested (Kenworthy et al., 1973; Beversdorf and Bingham, 1977). However, these events do not occur frequently enough to allow complete characterization.

The mechanism by which polyploid and polyembryonic seedlings arise first was investigated by Cutter and Bingham (1977). They examined 225 ovules of male-sterile plants and found normal embryo sacs at a frequency of $28 \%$. The most common abnormality was the presence of additional nuclei above the expected number of eight. It was postulated that polyembryony resulted from the genesis of multiple egg cells and that elevated ploidy levels arose through the fusion of the extra nuclei.

The origin of intraovular supernumerary nuclei was elucidated by Kennell and Horner (1985). The failure of postmeiotic cytokinesis during megasporogenesis resulted in the production of a four-nucleate megaspore. Typically, cytokinesis would lead to the formation of four uninucleate megapores, three of which degenerate. A large number of ovules subsequently abort; however, many undergo successive nuclear divisions, resulting in the production of a megagametophyte bearing 8 to 25 nuclei. The number of egg cells ranges from one to four. Interestingly, the number of synergids in the egg apparatus always is twice the number of eggs, regardless of the frequency of eggs in the ovule. Normal, eight-nucleate embryo sacs were generated either through the cessation of nuclear proliferation after one division or the infrequent completion of postmeiotic cytokinesis. Kennell and Horner (1985) also observed nuclear fusions, likely the origin of polyploidy.

The recovery of polyploids from $m s 1$ malesterile soybean may be attributed to an independence of endosperm and zygotic ploidy levels. Triploid soybean plants never have been recovered from crosses between male-fertile $4 n$ and $2 n$ plants, presumably a result of the failure 
of endosperm development (Sadanaga and Grindeland, 1981). Endosperm formation may be dependent on the occurrence of a 1:2 ratio of paternal : maternal genomes (Lin, 1984) or Mendelian factors (Johnston et al., 1980) in the primary endosperm nucleus. In a $4 n \times 2 n$ cross, the ratio would be improper (1:4). In an ms 1 megagametophyte, polyploids could develop if multiple egg nuclei fused before fertilization and if the endosperm nucleus retained the typical complement of two maternal genomes. Thus, double fertilization with pollen arising from a male-fertile diploid could result in the production of a normal triploid endosperm in the presence of a polyploid zygote. The occurrence of odd numbers of nuclei within the megagametophyte would allow this possibility. The recovery of haploids and polyploids from the indeterminate gametophyte system of maize was attributed to this mechanism of independent ploidy levels in egg and primary endosperm nuclei (Lin, 1984).

Polyploid seedlings possibly could arise if coenocytic microspores function as unreduced pollen grains. Any number of nuclei within the $\mathrm{CM}$ might fuse, giving rise to pollen of various ploidy levels. Elevated ploidy levels in the primary endosperm nucleus could result from multiple fusions of maternal nuclei, and could maintain a 1:2 ratio, even if sperm cells were generated from a $4 n$ nucleus. However, Chen and Palmer (1985) concluded, on the basis of the frequency of $M s 1 \mathrm{~ms} 1 \mathrm{~ms} 1$ and $\mathrm{ms} 1 \mathrm{~ms} 1 \mathrm{~ms} 1$ progeny among triploids derived from openpollinated $m s 1 m s 1$ plants, that all triploids arose via the fusion of haploid sperm, derived from male-fertile plants, with diploid eggs.

Though CM's can generate pollen tubes, direct observations of their participation in fertilization have not been obtained. Chen et al. (1987) recovered 35 seeds from $72 \mathrm{~ms} 1 \mathrm{~ms} 1$ plants grown in isolation. Thirty-one seeds germinated; two were tetraploid $(2 n=4 \times=80)$. The rest were diploid. All were homozygous recessive for $m s 1$ and male-sterile. Such seed could have arisen only through self-pollination through the function of CM's or via apomixis. Cytological observations, or tests using genetic markers, are necessary before the origin of such seed can be explained. The low frequency of "selfing," coupled with the absence of malesterile triploids in seed from open-pollinated male-sterile plants, suggests that polyploidy is largely a function of the female reproductive system of $m s 1$ plants.

As noted, six independent mutations have been recovered at the $m s l$ locus. The influence of these mutational events on female reproduction has been investigated. Boerma and
Cooper (1978) detected higher female fertility (measured by the number of seeds produced) when $m s 1$ (Urbana) was compared with $m s 1$ (North Carolina). Kennell and Horner (1985) determined the frequency of abnormal ovules in lines carrying $m s l$ (Ames 1 ), $m s l$ (Tonica), ms 1 (North Carolina), and $m s 1$ (Urbana) to be $70.6,60.4,67.9$, and $19.5 \%$, respectively. Chen et al. (1985) observed slight differences for the frequencies of polyembryony and polyploidy among these same four lines. However, they also noted that the frequency of polyploidy was altered when $m s l$ (Ames 1) and ms1 (Urbana) were placed in different genetic backgrounds. All studies comparing the various lines of $m s l$ are confounded by the fact that each is present in a unique genetic background. Thus, it is not possible to attribute different frequencies of abnormalities to differential effects of the mutations per se or to effects of different genetic environments acting on the $m s 1$ locus. The production of isogenic lines of the six independent mutations is required before definitive conclusions may be drawn.

The remaining male-sterile mutations have not been demonstrated to influence the female reproductive system to the extent of $m s 1$. Carter et al. (1986) have suggested a decrease in female fertility to be associated with $m s p$, but no cytological studies have been conducted. Sadanaga and Grindeland (1981) did recover five trisomics, one tetraploid, and one plant containing cells of variable chromosome numbers from $m s 2$ male-sterile plants. Whether these changes in chromosome number are the result of a pleiotropic effect of $m s 2$, genetic background, or chance remains to be demonstrated.

PARTIAL FERTILITY - Partial fertility refers to the breakdown of male sterility or to the facultative production of functional pollen by a plant of a male-sterile genotype. Partial fertility has been documented for the $m s p$ and $m s 4$ mutations and is suspected for $m s 1$ and $m s 5$. Male-sterile plants carrying either $m s 1$ or $m s 5$ frequently will produce a few seeds when grown in the absence of insect pollinators, though the origin of such seed is unclear.

Plants of the genotype $m s 4 m s 4$ generate, at a frequency of approximately $3.3 \%$, normal pollen capable of in vitro germination. Plants grown in isolation will set seed, and the response is temperature dependent (Graybosch and Palmer, 1984). Seed production of 0.5, 5.2, and 0.0 per plant was observed at day/night temperature regimes of $24 \mathrm{C} / 21 \mathrm{C}, 29 \mathrm{C} / 23 \mathrm{C}$, 
and 35 C/32 C. Graybosch and Palmer (1986) demonstrated self-pollination through the use of the chlorophyll-deficient marker allele $y 11$ and excluded apomixis as a possible means of seed production.

Caviness, Walters, and Johnson (1970) described a partially male-sterile soybean strain (the Arkansas male-sterile) conditioned by a recessive nuclear mutation. No gene symbol has been assigned to this mutation. The response to temperature was similar to that observed in the $m s 4$ system. Caviness and Fagala (1973) noted seed yields of $4.7,8.7$, and 0.0 per plant at temperature regimes of $21 \mathrm{C} / 16$ $\mathrm{C}, 29 \mathrm{C} / 21 \mathrm{C}$, and $35 \mathrm{C} / 27 \mathrm{C}$. Thus, high temperatures eliminate, and low temperatures reduce, male fertility in the Arkansas and $m s 4$ systems.

The most dramatic example of partial fertility is that associated with the msp mutation. Stelly and Palmer (1980a) observed male-fertile phenotypes when the $m s p$ allele was present in the homozygous condition. Stelly and Palmer (1980b) then demonstrated that plants of the genotype mspmsp would be completely sterile when grown under cool conditions (24 $\mathrm{C} / 18 \mathrm{C}$ or $24 \mathrm{C} / 21 \mathrm{C}$ ) but nearly completely self-fertile under warm temperatures $(35 \mathrm{C} / 27$ $\mathrm{C}$ or $35 \mathrm{C} / 32 \mathrm{C}$ ). Thus, msp allows the production of pure populations of male-sterile plants.

Carlson and Williams (1985) also have analyzed the response of $m s p$ to temperature. They grew mspmsp individuals under four temperature regimes. Daytime temperatures were identical in all test environments $(24 \mathrm{C})$, but nighttime temperatures of $15,18,21$, and 24 C were utilized. Results of this study demonstrate a highly significant correlation between decreasing night temperature and male fertility. Fertility was highest under the coolest nighttime conditions. At $15 \mathrm{C}$, fertility was $80 \%$ that of male-fertile controls. These results seemingly contrast with those of Stelly and Palmer (1980b). However, the extent of sterility may be a function, not of the absolute temperature, but of the difference between day and night temperatures. In both studies, the greater this difference, the greater the extent of male fertility.

The $m s p$ mutation allows one to control male sterility/fertility through the manipulation of environmental conditions. Thus, it provides an excellent tool for the study of the biochemical origins of male sterility. Stelly and Palmer (1982) noted that the timing of cytological abnormalities associated with $m s p$ was variable. This contrasts with the results obtained for the remaining male-sterile mutations, in which abortion occurs at a precise stage during the sequence of pollen development. It is not known how cytological development relates to temperature sensitivity of $m s p$. A study integrating cytological, biochemical, and agronomic aspects of $m s p$ would greatly enhance our knowledge of plant reproductive biology.

PHYSIOLOGICAL CHARACTERISTICS OF MALESTERILE PLANTS-Most investigations on the physiological nature of male-sterile soybean plants have not concentrated on biochemical aspects of anther development but have examined the influence of male sterility on "whole-plant" characteristics such as carbon and nitrogen metabolism and plant senescence. Male-sterile plants provide a means by which the effects of reduced reproductive load may be analyzed. When grown in the absence of pollen donors and vectors, plants homozygous recessive for $m s 1, m s 2$, or $m s 3$ will be seedless at maturity. Thus, researchers may avoid the laborious task of depodding normal male-fertile soybean plants when addressing the influence of seedlessness on plant metabolism.

The elimination of seed production by malesterile plants obviously leads to large pools of surplus photosynthate and nitrogenous compounds formed as a result of endosymbiotic nitrogen fixation. In male-fertile plants, pods and seeds act as sinks that accumulate these compounds. Investigations with male-sterile plants have focused on the fate of such metabolites and on the influence of accumulation on nitrogen fixation. Surplus photosynthate is not used in the production of additional vegetative or reproductive structures. Male-sterile plants are no larger, and have only slightly longer flowering periods, than male-fertile sibs. Burton, Wilson, and Brim (1979) determined the dry matter accumulation of male-sterile plants in relation to male-fertile plants and found no differences. Unused metabolites accumulate in plant organs as storage components and are not channeled into increased plant size. Excess nitrogen and carbohydrates accumulate in the leaves, stems, and roots of male-sterile plants (Burton et al., 1979). In the sterile plants, photosynthate is stored as starch in leaves and roots (Wilson et al., 1978). Root lipid content is three times that of male-fertile plants at maturity (Wilson, 1981).

The lack of excess vegetative growth also is related to the observations of Burke et al. (1984) on the nature of senescence in male-sterile plants. Soybean is a monocarpic annual; once the plant has flowered, senescence is imminent. Burke and coworkers found that $m s l$ malesterile plants still undergo senescence phenom- 
ena, even though the leaves retain chlorophyll beyond the time typical of male-fertile plants. Changes in leaf cellular RNA levels, phenolic compound concentrations, and acid protease activities in male-sterile plants parallel those of male-fertile plants. Male-fertile plants contain no chlorophyll at maturity; male-sterile plants retain $50 \%$ of the maximal chlorophyll accumulations. However, chlorophyll retention does not stimulate an elevated or extended rate of photosynthesis. Huber, Wilson, and Burton (1983) observed photosynthetic rates in male-fertile and male-sterile plants and concluded that those of male-sterile plants actually declined more rapidly. At maturity, photosynthesis in male-sterile plants is essentially absent, despite the presence of chlorophyll. Burke et al. (1984) suggested that the signal for monocarpic senescence is produced at flowering. Thus, even though male-sterile plants may be seedless, senescence is not avoided.

Increased availability of carbohydrate could possibly exert an effect on the process of nitrogen fixation. Nitrogen fixation typically declines after flowering (Sheehy, 1983), possibly the result of increased demand for carbohydrates in the seed having a higher priority than the demand in the nodules (Lawn and Brun, 1974). One might expect male-sterile plants to sustain a higher rate of nitrogen fixation because of extended availability of carbohydrate. Wilson et al. (1978) and Riggle, Wiebold, and Kenworthy (1984) studied nitrogen fixation rates in root nodules of $m s 1$ and $m s 2$ malesterile plants, respectively. Both studies failed to detect elevated rates in the male-sterile lines, but both observed a rate of decline in malesterile plants to be equal to that of male-fertile plants. Israel, Burton, and Wilson (1985) observed greater nitrogen concentrations in the aboveground tissues of male-sterile plants, in comparison with male-fertile plants, at the cessation of flowering. They suggested that the increased nitrogen content of stems and leaves created a type of feedback inhibition that depressed the rate of nitrogen fixation. Imsande and Ralston (1982), using $m s 4$ male-sterile plants, found enhanced nitrogen fixation in male-sterile plants, especially during the podfilling stage. The seemingly conflicting results of these investigators may be due to the unique male-sterile mutation and genetic background employed in each study and/or to the effects of different environments. The process of nitrogen fixation may be sensitive to genetic and environmental parameters to the extent that simultaneous study of several isogenic lines in a uniform environment is necessary before the true effect of male sterility can be assessed.
Musgrave, Antonovics, and Siedow (1986) recently found a correlation between the lack of cyanide-resistant respiration and male sterility in four plant species. They investigated this phenomenon in one male-sterile line of soybean ( $m s 1)$. Cyanide-resistant respiration was found to be lacking in male-sterile plants, but present in male-fertile lines. The authors noted that higher levels of cytokinins have been correlated with both male sterility and the absence of this form of respiration in several plant species. Thus, the absence of cyanide-resistant respiration may be a consequence of altered levels of growth regulators in male-sterile plants. A survey of the various male-sterile lines of soybean would be useful in determining the correlation between the absence of cyanideresistant respiration and male sterility. Because abortion of reproductive cells occurs at various times in the male-sterile lines, a common biochemical mechanism for sterility induction seems unlikely.

APPLICATIONS OF MALE STERILITY IN SOYBEAN-Observations on the effects of malesterility-inducing mutations have provided information on structures and processes vital to microsporogenesis and microgametogenesis. The available systems of male sterility in soybean also have proved useful in the areas of soybean genetics and breeding. The MS-FF mutations have been used in breeding programs as means to facilitate crossing experiments and increase the number of novel recombinant genotypes available for testing by breeders, to generate random mating populations for use in recurrent selection programs (Brim and Stuber, 1973), and to test the feasibility of commercial production of hybrid soybean seed. Male-sterile lines also may be used to facilitate the introgression of genes from primitive soybean lines into adapted modern cultivars (May and Wilcox, 1986). Carter, Burton, and Young (1983b) have developed a method that facilitates the backcrossing of MSFF characters into new genetic backgrounds. This method employs additional genetic markers as a means to follow the movement of the desired gene through several generations and does not require hand pollinations.

Two observations related to seed production by male-sterile plants are important to researchers contemplating the formation of random mating populations through the incorporation of male sterility. The seed yield of male-sterile plants will increase dramatically if naturally occurring insect populations are supplemented with the introduction of domestic bees (Carter et al., 1983b; Nelson and 
Bernard, 1984). Both honeybees and alfalfa leafcutter bees will transfer soybean pollen (Koelling, Kenworthy, and Caron, 1981). Second, May and Wilcox (1986) have determined that the frequency of pollen transfer from a given pollen parent to a male-sterile line is proportional to the frequency of that pollen parent in a crossing block. Thus, equal representation of several genotypes in the vicinity of a male-sterile line should result in equal frequencies of mating.

The production of hybrid soybean seed has been a subject of discussion among soybean workers since the first report of male sterility (Brim and Young, 1971). Three requirements must be satisfied before the production of hybrid soybean is possible: 1) significant yield increases must be realized in the $\mathrm{F} 1$ generation to justify the planting of more expensive hybrid seed over conventional inbred lines, 2) uniform populations of male-sterile soybean plants must be available to serve as female parents in crossing blocks, and 3) pollen transfer must occur between male-fertile pollen donors and male-sterile plants in hybrid production fields.

The available MS-FF mutations of soybean are nuclear mutations. Thus, they cannot be used in the production of uniform populations of male-sterile plants. Manipulations of partially fertile mutations might accomplish this task. However, there may be female sterility associated with the msp mutation (Carter et al., 1986), and the remaining partially fertile mutations produce too few seeds under permissive conditions to be of use in commercial programs.

Until either cytoplasmic male sterility or chemical hybridizing agents become available, use of the nuclear male-sterile mutations of soybean can provide information on levels of outcrossing and heterosis. Nelson and Bernard (1984) used MS-FF lines to produce F1 seed for testing of F1 heterosis. They were able to identify lines that provided levels of heterosis in excess of $15 \%$ increase above the highestyielding parent. These levels are of a magnitude that indicate the possibility of finding adequate levels of heterosis for commercial exploitation.

Boerma and Moradshahi (1975), Koelling et al. (1981), Carter, Burton, and Huie (1983a), and Carter et al. (1986) have used male-sterile lines to study the movement of insects within and between rows of soybean plants, the visitation of honeybees and leafcutter bees to soybean plants in caged plots, and levels of seed production in male-sterile soybeans planted under field conditions, respectively. Carter et al. have demonstrated seed yields of up to $80 \%$ that of male-fertile plants grown in the same environment (North Carolina).

Independent estimates of levels of outcrossing in various environments are important in determining the future of hybrid soybean. We observed seed production by several male-sterile lines in Missouri in 1985. The experiments were planted as a series of isolated crossing blocks. Experiment I (13 blocks, 5 male-sterile lines per block) was planted on 15 May 1985. Experiment II ( 4 blocks, 4 male-sterile lines per block) was planted on 30 June 1985 . The experiments were analyzed independently. Lines used carried one of the following malesterile mutations: $m s 1$ (Urbana), msl (North Carolina), $m s 2$, or $m s 3$. Three of the lines used (T266H, T259H, and T273H) were developed from the original genetic stocks and are maintained as pure lines segregating for male sterility. In addition, two near-isogenic lines, one with $m s 2$ (Williams $m s 2$ ) and one with $m s 1$ (North Carolina) (Clark $m s 1$ ) were used. Pollen parents used were commercially available cultivars or plant introductions (PI's) maintained by the USDA.

In each block, rows containing male-sterile plants were surrounded by a unique male-fertile line serving as pollen parent. Male-fertile plants were removed from the male-sterilecontaining rows at flowering. Both honeybees and leafcutter bees were placed in the field at densities of approximately 40,000 and 5,000 per hectare, respectively. Plants were harvested individually at maturity, and the number of seeds per plant was determined. Mean seed yields were determined for each combination of male-sterile by male-fertile line. Weighted means were calculated for each male-sterile parent (averaged over pollen parents). Differences then were compared through use of the Tukey-Kramer method for comparing means based on unequal sample sizes (Sokal and Rohlf, 1981). Seed yields also were expressed as a percentage of the average male-fertile plant grown in the same environment.

Data are presented in Tables 2 and 3. In Experiment $\mathrm{I}$, lines carrying $m s 2$ produced nearly twice as many seeds per plant as the remaining lines (Table 2). In Experiment II (Table 3) $m s 2$ and $m s 1$ (Urbana) significantly outyielded the remaining lines. These results may be due to differential pleiotropic effects of each mutation on attributes such as female fertility and floral attractiveness or may represent the effects of different genetic backgrounds or genotype $\times$ environment interactions. The differences observed between Clark $m s 1$ [ms 1 (North Carolina)] and T266H [ms 1 
TABLE 2. Seed production by male-sterile plants in Missouri, 1985. Experiment I, planting date = 15 May 1985. Data are given as seed per plant (mean) and number of plants sampled $(N)$

\begin{tabular}{|c|c|c|c|c|c|}
\hline \multirow[b]{2}{*}{ Pollen parent } & \multicolumn{5}{|c|}{ Male-sterile parent } \\
\hline & $\begin{array}{l}\mathrm{T} 266 \mathrm{H} \\
(m s I)\end{array}$ & Clark $m s I$ & Williams $m s 2$ & $\begin{array}{c}\mathrm{T} 259 \mathrm{H} \\
(m s 2)\end{array}$ & $\begin{array}{c}\mathrm{T} 273 \mathrm{H} \\
(m s 3)\end{array}$ \\
\hline $\begin{array}{l}\text { Elf mean } \\
\qquad N\end{array}$ & $\begin{array}{l}39.7 \\
11\end{array}$ & $\begin{array}{l}5.6 \\
8\end{array}$ & $\begin{array}{l}115.0 \\
19\end{array}$ & $\begin{array}{l}85.8 \\
18\end{array}$ & $\begin{array}{c}52.4 \\
9\end{array}$ \\
\hline Union & $\begin{array}{c}68.3 \\
3\end{array}$ & $\begin{array}{c}12.5 \\
2\end{array}$ & $\begin{array}{c}163.3 \\
12\end{array}$ & $\begin{array}{c}109.5 \\
4\end{array}$ & $\begin{array}{l}49.8 \\
12\end{array}$ \\
\hline Wayne & $\begin{array}{c}43.0 \\
9\end{array}$ & $\begin{array}{l}6.2 \\
10\end{array}$ & $\begin{array}{l}126.1 \\
14\end{array}$ & $\begin{array}{c}116.2 \\
17\end{array}$ & $\begin{array}{l}64.2 \\
14\end{array}$ \\
\hline T273H (fertile) ${ }^{1}$ & $\begin{array}{l}33.4 \\
21\end{array}$ & $\begin{array}{c}13.0 \\
8\end{array}$ & $\begin{array}{c}76.0 \\
2\end{array}$ & $\begin{array}{c}101.2 \\
11\end{array}$ & $\begin{array}{l}42.8 \\
15\end{array}$ \\
\hline PI 65379 & $\begin{array}{c}65.6 \\
9\end{array}$ & $\begin{array}{c}16.8 \\
4\end{array}$ & $\begin{array}{c}180.5 \\
15\end{array}$ & $\begin{array}{c}118.7 \\
9\end{array}$ & $\begin{array}{l}41.2 \\
13\end{array}$ \\
\hline PI 70212 & $\begin{array}{c}30.9 \\
7\end{array}$ & $\begin{array}{l}6.0 \\
2\end{array}$ & $\begin{array}{l}131.8 \\
10\end{array}$ & $\begin{array}{c}61.6 \\
9\end{array}$ & $\begin{array}{l}43.9 \\
16\end{array}$ \\
\hline PI 84656 & $\begin{array}{l}34.8 \\
15\end{array}$ & $\begin{array}{l}8.2 \\
5\end{array}$ & $\begin{array}{l}85.5 \\
20\end{array}$ & $\begin{array}{l}79.6 \\
15\end{array}$ & $\begin{array}{l}32.5 \\
16\end{array}$ \\
\hline PI 86136 & $\begin{array}{c}56.1 \\
9\end{array}$ & $\begin{array}{c}12.0 \\
9\end{array}$ & $\begin{array}{l}68.9 \\
21\end{array}$ & $\begin{array}{c}51.0 \\
6\end{array}$ & $\begin{array}{l}41.6 \\
14\end{array}$ \\
\hline PI 88456 & $\begin{array}{l}31.2 \\
12\end{array}$ & $\begin{array}{l}8.0 \\
2\end{array}$ & $\begin{array}{l}88.3 \\
10\end{array}$ & $\begin{array}{l}24.2 \\
11\end{array}$ & $\begin{array}{l}24.4 \\
18\end{array}$ \\
\hline PI 89061-2 & $\begin{array}{l}44.5 \\
13\end{array}$ & $\begin{array}{l}9.9 \\
10\end{array}$ & $\begin{array}{l}98.1 \\
14\end{array}$ & $\begin{array}{l}48.5 \\
13\end{array}$ & $\begin{array}{l}21.2 \\
23\end{array}$ \\
\hline PI 91750 & $\begin{array}{l}45.2 \\
11\end{array}$ & $\begin{array}{l}9.0 \\
6\end{array}$ & $\begin{array}{c}199.0 \\
6\end{array}$ & $\begin{array}{l}98.1 \\
16\end{array}$ & $\begin{array}{l}36.9 \\
18\end{array}$ \\
\hline PI 181554 & $\begin{array}{c}80.0 \\
7\end{array}$ & $\begin{array}{l}12.0 \\
20\end{array}$ & $\begin{array}{c}141.6 \\
14\end{array}$ & $\begin{array}{c}54.5 \\
2\end{array}$ & $\begin{array}{l}45.9 \\
15\end{array}$ \\
\hline PI 229738 & $\begin{array}{c}52.0 \\
2\end{array}$ & $\begin{array}{l}8.4 \\
9\end{array}$ & $\begin{array}{c}171.8 \\
5\end{array}$ & $\begin{array}{c}112.4 \\
5\end{array}$ & $\begin{array}{l}57.4 \\
12\end{array}$ \\
\hline $\begin{array}{l}\text { Weighted means }{ }^{2} \\
\text { Total } N\end{array}$ & $\begin{array}{l}48.1 \mathrm{bc} \\
129\end{array}$ & $\begin{array}{l}9.8 b c \\
95\end{array}$ & $\begin{array}{l}126.6 \mathrm{a} \\
162\end{array}$ & $\begin{array}{l}81.6 \mathrm{ab} \\
136\end{array}$ & $\begin{array}{l}42.6 b c \\
195\end{array}$ \\
\hline $\begin{array}{l}\% \text { Male-fertile } \\
\text { seed set }\end{array}$ & 19.2 & 3.9 & 50.6 & 32.6 & 17.0 \\
\hline
\end{tabular}

${ }^{1}$ Fertile (nonsegregating) isoline of $\mathrm{T} 273 \mathrm{H}$.

${ }^{2}$ Means followed by the same letter do not differ at the 0.05 level of significance.

(Urbana)] certainly are a function of the mutations per se. The genetic backgrounds of these two lines are similar (T266H was derived from Clark), and many studies have demonstrated increased female abnormalities in association with $m s 1$ (North Carolina). (See previous section on EFFECTS ON FEMALE FERTILITY.)

In the late-planted experiment, seed yields were drastically reduced for all male-sterile lines. This is due to a shorter growing season leading to smaller plants, fewer flowers per plant, and shorter flowering periods. In Experiment I, the average duration of the flowering period was $6 \mathrm{wk}$; in Experiment II, lines flowered for only $3 \mathrm{wk}$. Carter et al. (1983a) observed a similar reduction in seed yield in late-planted lines. In the lower midwestern and southern United States, soybeans often are planted as a second crop, usually after the harvest of winter wheat. Our results suggest that such plantings could not be used in hybrid seed production because of reduced seed sets.

Observations of field-grown male-sterile plants have suggested several management problems that may prevent the production of hybrid soybean seed. In most environments, naturally occurring insect populations must be supplemented by introductions. When natural populations alone are used, seed production by male-sterile plants is markedly reduced (Palmer, Albertsen, and Johns, 1983). Optimal environments must be located to maximize seed production. In Missouri, our highest-yielding male-sterile line produced only $50 \%$ the number of seeds as a normal male-fertile plant, while in North Carolina, Carter et al. (1983a) obtained yields of $80 \%$ that of male-fertile plants. Clearly, environments differ in their ability to facilitate outcrossing in soybean populations. Also, seed production within a given 
TABLE 3. Seed production by male-sterile plants in Missouri. Experiment II. Planting date = 30 June 1985. Data are given as per Table 2

\begin{tabular}{lcccc}
\hline \hline & \multicolumn{4}{c}{ Male-sterile parent } \\
\cline { 2 - 5 } \multicolumn{1}{c}{ Pollen parent } & $\begin{array}{c}\text { T266H } \\
(m s I)\end{array}$ & $\begin{array}{c}\text { Clark } \\
m s I\end{array}$ & $\begin{array}{c}\text { T259H } \\
(m s 2)\end{array}$ & $\begin{array}{c}\text { T273H } \\
(m s 3)\end{array}$ \\
\hline Calland mean & 12.6 & 1.4 & 4.5 & 2.1 \\
$N$ & 23 & 26 & 24 & 17 \\
Elf & 10.0 & 0.6 & 8.4 & 2.4 \\
& 15 & 9 & 33 & 18 \\
Union & 5.4 & 0.8 & 15.0 & 9.2 \\
& 14 & 19 & 34 & 20 \\
PI 181554 & 8.0 & 2.0 & 5.4 & 1.6 \\
& 13 & 22 & 24 & 14 \\
Weighted means & $9.5 \mathrm{a}$ & $1.3 \mathrm{~b}$ & $8.9 \mathrm{a}$ & $4.1 \mathrm{~b}$ \\
Total $N$ & 65 & 76 & 115 & 69 \\
\% Male-fertile & 11.8 & 1.6 & 11.0 & 5.1 \\
$\quad$ seed set & & & & \\
\hline
\end{tabular}

environment will fluctuate as a function of yearly climatic variation (Graybosch, Edge, and Delannay, 1987b). Observations of outcrossing levels in a variety of locations over several years are needed before the future of hybrid soybeans can be adequately ascertained.

Harvest operations also might be impaired in hybrid production fields. Unless seed yields on male-sterile plants are substantial, the plants do not dry and senesce properly. This will complicate mechanical harvesting and might necessitate the application of chemical drying agents. Seed quality on male-sterile plants often is poor, perhaps due to the atypical senescence. Senescence will approach that of male-fertile soybeans if seed set is high, but this will require the maintenance of sizable insect populations. Obviously, additional expense will be involved in the production of hybrid soybean and must be offset by substantial yield increases in the F1. Utilization of nuclear male-sterile soybeans in the testing of heterosis will be instrumental in determining the fate of hybrid soybean.

Lines carrying MS-FF mutations have been useful in a number of genetic and cytogenetic studies. The phenotypic appearance of malesterile plants at maturity provides an easily scored genetic marker useful in linkage studies. The production of plants of novel ploidy levels by $m s 1$ male-sterile plants has provided material for a number of cytogenetic analyses. Both haploids and triploids have been used to provide aneuploids, useful in chromosome mapping experiments (Beversdorf and Bingham, 1977; Chen and Palmer, 1985). Meiotic chromosome pairing has been studied in haploids (Crane, Beversdorf, and Bingham, 1982) and triploids (Chen and Palmer, 1985). The occurrence of bivalents in haploids, tetravalents and hexavalents in triploids, and secondary associations in both types supports the hypothesis of Bernard and Weiss (1973) that the soybean genome arose via polyploidization.

In summary, the MS-FF mutations have provided extensive information on reproductive and physiological phenomena in soybean and have proved to be useful in soybean genetics and breeding. The exact gene products encoded by these loci remain unknown; however, the timing of action of these gene products has been identified. Integration of this information with biochemical studies should enhance our knowledge of plant reproductive biology and lead to a greater understanding of the phenomenon of male sterility in plants.

\section{LITERATURE CITED}

Albertsen, M. C., AND R. G. Palmer. 1978. A comparative light- and electron microscope study of $\mathrm{mi}$ crosporogenesis in male-sterile ( $m s 1)$ and male-fertile soybeans [Glycine max (L.) Merr.]. Amer. J. Bot. 66: 253-265.

BERNARD, R. L., AND M. G. WeISS. 1973. Qualitative genetics. In B. E. Caldwell [ed.], Soybeans: improvement, production and uses, 117-154. Amer. Soc. Agron., Madison, WI.

Beversdorf, W. D., And E. T. Bingham. 1977. Male sterility as a source of haploids and polyploids of $G l y$ cine max. Canad. J. Genet. Cytol. 19: 283-287.

Boerma, H. R., AND R. L. CoOPER. 1978. Increased female fertility associated with the $m s l$ locus in soybeans. Crop Sci. 18: 344-346.

— AND A. MORADSHAHI. 1975. Pollen movement within and between rows to male-sterile soybeans. Crop Sci. 15: 858-861.

Brim, C. A., AND C. W. Stuber. 1973. Application of genetic male sterility to recurrent selection schemes in soybeans. Crop Sci. 13: 528-530.

- AND M. F. YOUNG. 1971. Inheritance of a male sterile character in soybeans. Crop Sci. 11: 564-566.

Buntman, D. J., AND H. T. Horner. 1983. Microsporogenesis of normal and $m s 3$ mutant soybean (Glycine max). Scanning Electron Microsc./1983/Part II: 913922.

Burke, J. J., W. Kalt-Torres, J. R. Swafford, J. W. Burton, AND R. F. WiLson. 1984. Studies on genetic male-sterile soybeans. III. The initiation of monocarpic senescence. Pl. Physiol. 75: 1058-1063.

Burton, J. W., R. F. Wilson, AND C. A. Brim. 1979. Dry matter and nitrogen accumulation in male-sterile and male-fertile soybeans. Agron. J. 71: 548-552.

Buss, G. R. 1983. Inheritance of a male-sterile mutant from irradiated Essex soybean. Soybean Genet. Newsl. 10: 104-108.

Carlson, D. R., and C. B. Williams III. 1985. Effect of temperature on the expression of male sterility in partially male-sterile soybean. Crop Sci. 25: 646-648.

Carter, T. E., Jr., G. Bran, J. W. Burton, and A. L. FONSECA. 1986. Seed yield on field-grown $m s 2$ malesterile plants. Soybean Genet. Newsl. 13: 159-163. , J. W. Burton, AND E. B. Huie, JR. 1983a. Im- 
plications of seed set on $m s 2 m s 2$ male-sterile plants in Raleigh. Soybean Genet. Newsl. 10: 85-87.

- , AND M. F. Young. 1983b. An efficient method for transferring genetic male sterility to soybean lines. Crop Sci. 23: 387-388.

Caviness, C. E., AND B. L. Fagala. 1973. Influence of temperature on a partially male-sterile soybean strain. Crop Sci. 13: 503-504.

—, H. J. WAlters, AND D. L. Johnson. 1970. A partially male sterile strain of soybean. Crop Sci. 10: 107-108.

Chaudhari, H. K., AND W. H. Davis. 1977. A new malesterile strain in Wabash soybeans. J. Hered. 68: 266277.

Chen, L. F. O., M. C. Albertsen, and R. G. Palmer. 1987. Pollen and coenocytic microspore germination in male-fertile and male-sterile $m s l$ soybean. Euphytica 36: 333-343.

$\longrightarrow$, H. E. Heer, and R. G. Palmer. 1985. The frequency of polyembryonic seedlings and polyploids from $m s 1$ soybean. Theor. Appl. Genet. 69: 271-277.

- AND R. G. PALMER. 1985. Cytological studies of triploids and their progeny from male-sterile ( $m s l$ ) soybean. Theor. Appl. Genet. 71: 400-407.

Crane, C. F., W. D. Beversdorf, and E. T. Bingham. 1982. Chromosome pairing and associations at meiosis in haploid soybean (Glycine max). Canad. J. Genet. Cytol. 24: 293-300.

Cutter, G. L., And E. T. Bingham. 1977. Effect of soybean male-sterile gene $m s l$ on organization and function of the female gametophyte. Crop Sci. 17: 760764.

Davis, W. H. 1985. Route to hybrid soybean production. United States Patent 4,545,146.

Delannay, X., and R. G. Palmer. 1982. Genetics and cytology of the $m s 4$ male-sterile soybean. J. Hered. 73: 219-223.

ERICKSON, E. H. 1975. Variability of floral characteristics influences honey bee visitation to soybean blossoms. Crop Sci. 15: 767-771.

— AND M. B. Garment. 1979. Soya-bean flowers: nectary ultrastructure, nectar guides, and orientation on the flower by foraging honeybees. J. Apic. Res. 18: 3-11.

Graybosch, R. A., R. L. Bernard, C. R. Cremeens, and R. G. PALMER. 1984. Genetic and cytological studies of a male-sterile, female-fertile soybean mutant. J. Hered. 75: 383-388.

- M. E. Edge, And X. Delannay. 1987a. Somaclonal variation in soybean plants regenerated from the cotyledonary node tissue culture system. Crop Sci. 27: 803-806.

$\longrightarrow,-$ AND — 1987b. Seed production by male-sterile soybeans in Missouri. Soybean Genet. Newsl. 14: 156-160.

- AND R. G. PALMER. 1984. Is the ms 4 male-sterile mutant partially fertile? Soybean Genet. Newsl. 11: 101-104.

, AND - 1985a. Male sterility in soybean (Glycine max). I. Phenotypic expression of the $m s 2$ mutant. Amer. J. Bot. 72: 1738-1750.

$\longrightarrow$, AND - 1985b. Male sterility in soybean (Glycine max). II. Phenotypic expression of the $m s 4$ mutant. Amer. J. Bot. 72: 1751-1764.

$\longrightarrow$, AND $\longrightarrow$. 1986. Test for apomixis in $m s 4$ male-sterile soybean. Soybean Genet. Newsl. 13: 143144.

— AND —. 1987. Analysis of a male-sterile character from Glycine $\max (\mathrm{L}$.$) Merr. cv Wabash$ (soybean). J. Hered. 76: 66-70.

Hadley, H. H., and W. J. Starnes. 1964. Sterility in soybeans caused by asynapsis. Crop Sci. 4: 421-424.

Horner, H. T., AND C. B. Pearson. 1978. Pollen wall and aperture development in Helianthus annuus (Compositae: Heliantheae). Amer. J. Bot. 65: 293309.

Huber, S. C., R. F. Wilson, And J. W. Burton. 1983. Studies on genetic male-sterile soybeans. II. Effect of nodulation on photosynthesis and carbon partitioning in leaves. Pl. Physiol. 73: 713-717.

ImSANDE, J., AND E. J. RALSTon. 1982. Dinitrogen fixation in male-sterile soybeans. Pl. Physiol. 69: 745746.

ISRAEL, D. W., J. W. BURTON, AND R. F. WILSON. 1985. Studies on genetic male-sterile soybeans. IV. Effect of male sterility and source of nitrogen nutrition on accumulation, partitioning, and transport of nitrogen. Pl. Physiol. 78: 762-767.

Johns, C. W., AND R. G. PAlmer. 1982. Floral development of a flower-structure mutant in soybeans, Glycine $\max$ (L.) Merr. (Leguminosae). Amer. J. Bot. 69: 829-842.

Johnston, S. A., T. P. M. Den Niss, S. J. Peloquin, And R. E. HANNEMAN, JR. 1980. The significance of genic balance to endosperm development in interspecific crosses. Theor. Appl. Genet. 57: 5-9.

Kennell, J. C., AND H. T. Horner. 1985. Influence of the soybean male-sterile gene ( $m s l$ ) on the development of the female gametophyte. Canad. J. Genet. Cytol. 27: 200-209.

Kenworthy, W. J., C. A. Brim, and E. A. Wernsman. 1973. Polyembryony in soybeans. Crop Sci. 13: 637639.

Koelling, P. D., W. J. Kenworthy, and D. M. Caron. 1981. Pollination of male-sterile soybeans in caged plots. Crop Sci. 21: 559-561.

LAwn, R. J., AND W. A. BrUN. 1974. Symbiotic nitrogen fixation in soybeans. I. Effects of photosynthetic sourcesink manipulations. Crop Sci. 14: 11-16.

LIN, B. Y. 1984. Ploidy barrier to endosperm development in maize. Genetics 107: 103-115.

MAY, M. L., AND J. R. WILCOX. 1986. Pollinator density effects on frequency and randomness of male-sterile soybean pollinations. Crop Sci. 26: 96-99.

Musgrave, M. E., J. Antonovics, and J. N. Siedow. 1986. Is male-sterility in plants related to lack of cyanide-resistant respiration in tissues? Pl. Sci. 44: 711.

Nakashima, H., H. T. Horner, And R. G. Palmer. 1984. Histological features of anthers from normal and $m s 3$ mutant soybean. Crop Sci. 24: 735-739.

Nelson, R. L., AND R. L. Bernard. 1984. Production and performance of hybrid soybeans. Crop Sci. 24: 549-553.

Newell, C. A., AND T. Hymowitz. 1983. Hybridization in the genus Glycine subgenus Glycine Willd. (Leguminosae, Papilionoideae). Amer. J. Bot. 70: 334-348.

PAlmer, R. G. 1974a. A desynaptic mutant in soybeans. J. Hered. 65: 280-286.

- 1974b. Aneuploids in the soybean, Glycine max. Canad. J. Genet. Cytol. 16: 441-447.

- M. C. Albertsen, and H. Heer. 1978b. Pollen production in soybeans with respect to genotype, environment and stamen position. Euphytica 27: 427433.

—_ M. C. Albertsen, And C. W. Johns. 1983. Pollen 
movement to two male-sterile soybean mutants grown in two locations. J. Hered. 74: 55-57.

$\longrightarrow$, AND H. HeER. 1976. Aneuploids from a desynaptic mutant in soybeans [Glycine max (L.) Merr.]. Cytologia 41: 417-427.

- C. W. Johns, AND P. S. MuIr. 1980. Genetics and cytology of the ms 3 male-sterile soybean. J. Hered. 71: 343-348.

—, AND M. L. H. Kaul. 1983. Genetics, cytology and linkage studies of a desynaptic soybean mutant. J. Hered. 74: 260-264.

, C. L. Winger, And M. C. Albertsen. 1978a. Four independent mutations at the $m s l$ locus in soybeans. Crop Sci. 18: 727-729.

Riggle, B. D., W. J. Wiebold, AND W. J. Kenworthy. 1984. Effect of photosynthate source-sink manipulation on dinitrogen fixation of male-fertile and malesterile soybean isolines. Crop Sci. 24: 5-8.

SACKS, J. M., AND K. SADANAGA. 1984. Linkage between the male sterility gene $(m s l)$ and a translocation breakpoint in soybean, Glycine max. Canad. J. Genet. Cytol. 26: 401-404.

SADANAGA, K., AND R. GRINDELAND. 1981. Natural crosspollination in diploid and autotetraploid soybeans. Crop Sci. 21: 503-506.

SHeEHY, J. H. 1983. Relationships between senescence, photosynthesis, nitrogen fixation and seed filling in soya bean, Glycine $\max$ (L.) Merr. Ann. Bot. 51: 678682.

Sheldon, J. M., ANd H. G. Dickinson. 1983. Determination of patterning in the pollen wall of Lilium henryi. J. Cell Sci. 63: 191-208.

- AND $\longrightarrow$ 1986. Pollen wall formation in Lilium: the effects of chaotropic agents, and the organization of the microtubular cytoskeleton during pattern development. Planta 168: 11-23.
SKORUPSKA. H.. AND J. NAwRACALA. 1980. Observations of pollen grains of soybean plants in the male-sterile line Urbana $m s 1$. Genet. Pol. 21: 63-68.

- AND R. G. PALMER. 1987. New independent mutation: $m s 1$ (Ames 2). Soybean Genet. Newsl. 14: 181182.

SOKAL, R. R., AND F. J. Rohlf. 1981. Biometry. W. H. Freeman, San Francisco.

Stelly, D. M., AND R. G. Palmer. 1980a. A partially male-sterile mutant line of soybeans, Glycine max (L.) Merr.: inheritance. Euphytica 29: 295-303.

$\longrightarrow$, AND 1980 b. A partially male-sterile mutant line of soybeans, Glycine max (L.) Merr.: characterization of the $m s p$ phenotype variation. Euphytica 29: 539-546.

$\longrightarrow$, AND -1982 . Variable development in anthers of partially male-sterile soybeans. J. Hered. 73: 101-108.

VAn Lammeren, A. A. M., C. J. KeiJzer, M. T. M. WilLEMSE, AND H. KIEFT. 1985. Structure and function of the microtubular cytoskeleton during pollen development in Gasteria verrucosa (Mill.) $\mathrm{H}$. Duval. Planta 165: 1-11.

Wilson, R. F. 1981. Root lipid composition and metabolism in genetic male-sterile soybeans. Crop Sci. 21: 69-73.

, J. W. Burton, J. A. Buck, And C. A. Brim. 1978. Studies on genetic male-sterile soybeans. I. Distribution of plant carbohydrate and nitrogen during development. Pl. Physiol. 61: 838-841.

YEE, C., AND L. JIAN. 1983. Allelism tests of Shennong male-sterile soybean L-78-387. Second Assembly Symp. Genet. Soc. China. Sec. 4. No. 053. 241-242. (In Chinese.) 